\title{
Delayed Graft Function
}

National Cancer Institute

\section{Source}

National Cancer Institute. Delayed Graft Function. NCI Thesaurus. Code C114853.

The need for dialysis within a week of kidney transplant. 